\title{
Optimal Debt Management in a Liquidity Trap
}

H. Bouakez, R. Oikonomou and R. Priftis

Discussion Paper 2016-5

\section{Institut de Recherches Économiques et Sociales de l'Université catholique de Louvain}

IRES 


\title{
Optimal Debt Management in a Liquidity Trap
}

\author{
Hafedh Bouakez* $\quad$ Rigas Oikonomou ${ }^{\dagger} \quad$ Romanos Priftis ${ }^{\ddagger}$
}

January 2016

\begin{abstract}
We study optimal debt management in the face of shocks that can precipitate the economy into a liquidity trap and call for an increase in public spending in order to mitigate the resulting recession. Our approach follows the sizable literature of macroeconomic models of debt management, which we extend to the case where the zero lower bound on the short-term interest rate binds. We wish to identify the conditions under which removing long debt from the secondary market can become an optimal policy outcome. We show that the optimal debt-management strategy is to issue short-term debt if the government faces a sizable exogenous increase in public spending and if its initial liability is not very large. In this case, our results run against the standard prescription of the debt-management literature. Finally, we show that when the government sets optimally the level of public spending, the optimality of long-term debt is restored.
\end{abstract}

\section{JEL Classification : E43, E62, H63}

Keywords: Debt Management, Debt Maturity, Fiscal Policy, Liquidity Trap, Monetary Policy, Tax Smoothing.

*Department of Applied Economics and CIRPÉE, HEC Montréal, 3000 chemin de la Côte-Sainte-Catherine, Montréal, Québec, Canada H3T 2A7. E-mail: hafedh.bouakez@hec.ca.

${ }^{\dagger}$ Université Catholique de Louvain. IRES-CORE, Université Catholique de Louvain, Collège L. H. Dupriez, 3 Place Montesquieu 1348 Louvain la Neuve, Belgium. Email: rigas.oikonomou@uclouvain.be.

${ }_{\ddagger}^{\ddagger}$ Modelling Unit, Directorate General for Economic and Financial Affairs, European Commission, Rue de la Loi 170, Brussels 1049, Belgium. Email: romanos.priftis@ec.europa.eu. 


\section{Introduction}

A well known characteristic of the policy response to the recent economic recession in the U.S. has been the large-scale purchases of long-term government debt by the Federal Reserve when short-term rates approached the zero lower bound (ZLB); a situation often referred to as a liquidity trap. At the same time, a considerable fiscal expansion took place, leading to sizable deficits and a mounting debt level. These patterns have been observed in several other industrialized economies.

A substantive literature has studied the optimal maturity structure in macroeconomic models (e.g., Angeletos (2002) and Buera and Nicolini (2006), hereafter ABN) and reached the conclusion that governments should only issue long-term debt when faced with shocks to public spending and productivity. ${ }^{1}$ Long debt provides a hedging value, which enables governments to smooth tax distortions over time. This research might therefore suggest that the recent interventions by central banks in the secondary market have moved the actual maturity structure (in the hands of the private sector) further away from the optimal policy benchmark.

The purpose of this paper is to study optimal debt management in an economy that faces the risk of falling into a liquidity trap, which would be accompanied by an increase in the public deficit in order to mitigate the impact of the resulting recession. Following several papers (e.g., Eggertsson and Woodford (2003, EW), Christiano, Eichenbaum and Rebelo (2011, CER)), we assume that the economy may fall into a liquidity trap following a preference shock that lowers the weight attached to current utility and induces agents to postpone consumption. When prices are sticky and monetary policy is constrained by the ZLB, this shock yields a drop in current consumption and output. The model we develop is broadly similar to those proposed by Schmitt-Grohé and Uribe (2004, SGU), and Faraglia, Marcet, Oikonomou and Scott (2013, FMOS): we assume that monetary and fiscal policies are coordinated, and that the planner can control inflation and distortionary taxes. In our model, however, the planner can also issue debt in different maturities.

We show that the price of government bonds rises in response to the preference shock discussed above. Whether the optimal debt-management strategy is to issue long or short debt depends on the response of the present value of government surpluses. The latter in turn hinges crucially on the level of initial debt and on the properties of public spending shocks. We find that short-term debt is optimal when the government faces large and persistent exogenous increases in public spending and when its initial liability is not too large. Otherwise, the government prefers to issue long-term debt.

We then ask: what happens when spending levels are chosen optimally by the government? We find that across all debt levels, the government chooses to issue long bonds to benefit from fiscal hedging. The reason is that when public expenditures are set to maximize the household's welfare, they rise very little when the preference shock hits, and fall subsequently. The dynamic responses of public spending and taxes in this case are such that the present value of government's surpluses always rises with the preference shock, which, as we show, implies that short-term debt is sub-optimal. To summarize, shortening the maturity structure may be optimal when public spending is exogenous (and inefficiently large); however, when the latter is chosen optimally, we reach the opposite prescription: governments should finance long.

This paper proceeds as follows: Section 2 presents the model and the planning program. Section 3 analytically derives key features of the optimal allocation and the portfolio. Section 4 presents the results based on numerical simulations. Section 5 presents the extension with optimal public spending. A final section concludes.

\footnotetext{
${ }^{1} \mathrm{ABN}$ were the first to show that governments want to issue long bonds to hedge against public spending and productivity shocks. Faraglia, Marcet and Scott (2010) allow for habit preferences and capital accumulation and show that the result remains. Nosbusch (2008) and Lustig, Sleet and Yeltekin (2008) assume incomplete markets; their conclusion is (again) that long-term debt is optimal.
} 


\section{Model}

\subsection{Agents}

Preferences We consider an infinite horizon economy, populated by a representative household with preferences defined by

$$
E_{0}\left(\sum_{t=0}^{\infty} \beta^{t}\left(u\left(c_{t}, \xi_{t}\right)+v\left(h_{t}, \xi_{t}\right)\right)\right)
$$

where $c_{t}$ denotes consumption, $h_{t}$ denotes hours, and $\beta$ is the discount factor. The term $\xi_{t}$ represents a shock to preferences that we will model as in EW. More specifically, we assume that $u\left(c_{t}, \xi_{t}\right)=\xi_{t} u\left(c_{t}\right)$ and $v\left(h_{t}, \xi_{t}\right)=\xi_{t} v\left(h_{t}\right)$. A drop in $\xi_{t}$ relative to $\xi_{t+j}, j=1,2 \ldots$ implies that the household wants to postpone consumption (and leisure) to the future.

Firms The consumption good is produced by a representative, perfectly competitive, final-good producer using a Dixit-Stigltiz aggregator of a continuum of differentiated intermediate products. The production of a generic intermediate product $i$ is carried out by a monopolistically competitive firm using a linear technology $y_{i, t}=h_{i, t}$. The demand for product $i$ is given by $Y_{t} d\left(P_{i, t} / P_{t}\right)$, where $P_{i, t}$ is the price of intermediate product $i, P_{t}$ is the price of the composite final good, and $Y_{t}$ is output in the final-good sector. The demand function, $d$, satisfies additional assumptions that guarantee the existence of a symmetric equilibrium, namely, $d(1)=1$ and $d^{\prime}(1) \equiv \eta<-1$.

We assume that the prices of intermediate goods are costly to adjust. Following Rotemberg (1982), adjustment costs are given by $\frac{\theta}{2}\left(\frac{P_{i, t}}{P_{i, t-1}}-1\right)^{2}$, where $\theta \geq 0$ governs the degree of price stickiness. When $\theta=0$ prices are fully flexible. When $\theta \rightarrow \infty$ prices will remain constant through time.

Intermediate-good producers seek to maximize

$$
E_{t} \sum_{j=0}^{\infty} \beta^{j} \frac{u_{c}\left(c_{t+j}, \xi_{t+j}\right)}{u_{c}\left(c_{t}, \xi_{t}\right)}\left\{\frac{P_{i, t+j}}{P_{t+j}} Y_{t+j} d\left(\frac{P_{i, t+j}}{P_{t+j}}\right)-w_{t+j} h_{i, t+j}-\frac{\theta}{2}\left(\frac{P_{i, t+j}}{P_{i, t+j-1}}-1\right)^{2}\right\}
$$

subject to the constraint $h_{i, t+j}=Y_{t+j} d\left(P_{i, t+j} / P_{t+j}\right)$. From the firm's first-order condition we can derive the following Phillips curve in a symmetric equilibrium:

$$
\left(\pi_{t}-1\right) \pi_{t}=\frac{\eta}{\theta}\left(\frac{1+\eta}{\eta}-w_{t}\right) Y_{t}+\beta E_{t} \frac{u_{c}\left(c_{t+1}, \xi_{t+1}\right)}{u_{c}\left(c_{t}, \xi_{t}\right)}\left(\pi_{t+1}-1\right) \pi_{t+1}
$$

where $\pi_{t}=\frac{P_{t}}{P_{t-1}}$ denotes gross inflation.

Government and Markets The government engages in two activities - it levies taxes on households' labor income and, second, it trades with households in bond markets to finance a spending process $\left\{g_{t}\right\}_{0}^{\infty}$. We denote labor income taxes by $\tau_{t}$. Moreover, let $B_{t}^{j}$ be the quantity of a bond that promises to pay a unit of income in $t+j$ and is issued in period $t$. Let the price be $q_{t}^{j}$. For simplicity, denote by $\mathcal{J}$ the set of available maturities. ${ }^{2}$

We study an economy in which government bonds can complete the markets. Thus, it becomes immaterial whether the government redeems the outstanding bonds at maturity or whether it buys back debt in every period and then reissues. The latter assumption is followed by many papers in the literature (see, for example, ABN, FMOS (2015) among others). For simplicity, we will follow this setup. The

\footnotetext{
${ }^{2}$ This object will be specified later. Notice that even though we can have $\mathcal{J} \equiv\{1,2, \ldots, \bar{j}\}$, that is, allow the government to trade with any maturity ranging from one period to some maximum length $\bar{j}$, in practice we will not need all of these trades to be realized. Since there will be only two states of shocks, it suffices to have $\mathcal{J}=\{1, N\}$ (a one-period bond and an $N$-period bond).
} 
government budget constraint can thus be written as

$$
\sum_{j \in \mathcal{J}} q_{t}^{j} B_{t}^{j}=\sum_{j \in \mathcal{J}} q_{t}^{j-1} B_{t-1}^{j}+P_{t}\left(g_{t}-\tau_{t} w_{t} h_{t}\right)
$$

The initial debt level of the government will be denoted by $\widetilde{B}_{-1}$.

Household Optimization. Given the policies described above, the household maximizes utility (1) subject to the sequence of budget constraints

$$
\sum_{j \in \mathcal{J}} q_{t}^{j} B_{t}^{j, H}=\sum_{j \in \mathcal{J}} q_{t}^{j-1} B_{t-1}^{j, H}+P_{t}\left(1-\tau_{t}\right) w_{t} h_{t}-P_{t} c_{t}
$$

where $B_{t}^{j, H}$ represents the quantity of debt of maturity $j$ demanded by the household in $t$. From the household's optimization we can derive the following optimality conditions:

$$
\begin{gathered}
\left(1-\tau_{t}\right) w_{t}=-\frac{v_{h}\left(h_{t}, \xi_{t}\right)}{u_{c}\left(c_{t}, \xi_{t}\right)}, \\
q_{t}^{j}=\beta^{j} E_{t} \frac{u_{c}\left(c_{t+j}, \xi_{t+j}\right) P_{t}}{u_{c}\left(c_{t}, \xi_{t}\right) P_{t+j}},
\end{gathered}
$$

and $q_{t}^{0}=1 .^{3}$

\subsection{Uncertainty}

Our goal is to determine debt management policies in the case where the ZLB constraint may bind. We therefore assume that in period 1 the economy can be hit by a shock that lowers $\xi_{1}$ sufficiently relative to $\xi_{2}$ so as to make the ZLB bind $\left(q_{1}^{1}=1\right)$. After this shock occurs, there are no further shocks to the economy and the adjustment of $\xi_{t}$ follows $\xi_{t}=\rho_{\xi} \xi_{t-1}+\left(1-\rho_{\xi}\right)$ where $\rho_{\xi} \geq 0$. The preference shock occurs with probability 0.5 ; if it is not realized we have that $\xi_{t}=1$ for all $t$.

Turning to the process of public spending which, for now, is considered to be exogenous, we assume the following:

Assumption 1 If a negative preference shock hits (making the ZLB bind), then $g_{1}$ may increase above its steady state-value, $\bar{g}$. In this case, the adjustment of public spending in subsequent periods follows $g_{t}=\rho_{g} g_{t-1}+\left(1-\rho_{g}\right) \bar{g}$. Otherwise, spending remains constant: $g_{t}=\bar{g}$ for all $t$.

As will become evident in section 5, the increase in public spending in response to a preference shock that makes the ZLB bind can be rationalized in the context of an economy in which public expenditures are chosen optimally by the planner.

\subsection{The Ramsey Problem}

We assume that the government maximizes the household's utility under full commitment (as in ABN, SGU, FMOS). We follow the primal approach; we eliminate the tax rate and the bond prices from the program using the equilibrium expressions for these objects. Moreover, since we assume complete markets, we can solve the Ramsey problem by maximizing the household's utility subject to the following date 0

\footnotetext{
${ }^{3}$ Notice that since we assume a representative household, the prices $q_{t}^{j}$ are the prices of bonds in the secondary market. When the government buys outstanding debt in the market it has to pay $q_{t}^{j}$ to the household.
} 
intertemporal budget constraint of the government: ${ }^{4}$

$$
E_{0} \sum_{t=0}^{\infty} \beta^{t} E_{t} \frac{u_{c}\left(c_{t+j}, \xi_{t+j}\right)}{u_{c}\left(c_{t}, \xi_{t}\right)}\left[-g_{t}+\left(1+\frac{v_{h}\left(h_{t}, \xi_{t}\right)}{u_{c}\left(c_{t}, \xi_{t}\right) w_{t}}\right) w_{t} h_{t}\right]=\widetilde{B}_{-1} .
$$

The remaining constraints are the Phillips curve, the resource constraint and the ZLB.

Optimality Let $\widetilde{\lambda} \equiv\left(\lambda_{s}, \lambda_{p, t}, \lambda_{f, t}, \lambda_{Z L B, t}\right)$ denote the vector of Lagrange multipliers (on the intertemporal budget, the Phillips curve, the resource constraint, and the ZLB, respectively). Denoting by $s_{t} \equiv-g_{t}+\left(1+\frac{v_{h}\left(h_{t}, \xi_{t}\right)}{u_{c}\left(c_{t}, \xi_{t}\right) w_{t}}\right) w_{t} h_{t}$ the government's surplus in $t$ and by $\mathcal{I}$ the indicator function, the optimal allocation can be approximated as a solution to the following system:

$$
\begin{gathered}
u_{c}\left(c_{t}, \xi_{t}\right)-\lambda_{f, t}-\lambda_{Z L B, t} u_{c c}\left(c_{t}, \xi_{t}\right)+\lambda_{Z L B, t-1} \frac{u_{c c}\left(c_{t}, \xi_{t}\right)}{\pi_{t}}-\left(\lambda_{p, t}-\lambda_{p, t-1}\right) u_{c c}\left(c_{t}, \xi_{t}\right) \pi_{t}\left(\pi_{t}-1\right) \\
+\lambda_{p, t} \frac{\eta}{\theta} h_{t} u_{c c}\left(c_{t}, \xi_{t}\right)\left(\frac{1+\eta}{\eta}-w_{t}\right)-\lambda_{s} u_{c c}\left(c_{t}, \xi_{t}\right) s_{t}-\lambda_{s} u_{c}\left(c_{t}, \xi_{t}\right) s_{c, t}+\lambda_{s} u_{c}\left(c_{0}, \xi_{0}\right) \widetilde{B}_{-1} \mathcal{I}_{t=0}=0 \\
v_{h}\left(h_{t}\right)+\lambda_{f, t}-\lambda_{s} u_{c}\left(c_{t}, \xi_{t}\right) s_{h, t}+\lambda_{p, t} \frac{\eta}{\theta} u_{c}\left(c_{t}, \xi_{t}\right)\left(\frac{1+\eta}{\eta}-w_{t}\right)=0 \\
-\theta \lambda_{f, t}\left(\pi_{t}-1\right)-\left(\lambda_{p, t}-\lambda_{p, t-1}\right) u_{c}\left(c_{t}, \xi_{t}\right)\left(2 \pi_{t}-1\right)-\lambda_{Z L B, t-1} \frac{u_{c}\left(c_{t}, \xi_{t}\right)}{\pi_{t}^{2}}=0 \\
\lambda_{s} s_{w, t}-\frac{\eta}{\theta} \lambda_{p, t} h_{t}=0
\end{gathered}
$$

where $s_{c, t} \equiv \frac{v_{h}\left(c_{t}+\bar{g}\right)}{u_{c}\left(c_{t}\right)^{2}} u_{c c}\left(c_{t}\right)\left(c_{t}+\bar{g}\right)$ and $s_{h, t}=\frac{v_{h h}\left(c_{t}+\bar{g}\right)}{u_{c}\left(c_{t}\right)}\left(c_{t}+\bar{g}\right)+\left(1+\frac{v_{h}\left(c_{t}+\bar{g}\right)}{u_{c}\left(c_{t}\right)} \frac{\eta}{1+\eta}\right) \frac{1+\eta}{\eta}$, and $s_{w, t}=h_{t}$. From complementary slackness we have

$$
\lambda_{Z L B, t}\left(u_{c}\left(c_{t}, \xi_{t}\right)-\beta E_{t} \frac{u_{c}\left(c_{t+1}, \xi_{t+1}\right)}{\pi_{t+1}}\right)=0
$$

\section{Analytical Results}

\subsection{Long-run distortion smoothing}

We begin by highlighting two important results that hold when the ZLB ceases to bind.

Proposition 1. Price stability Assume that the $Z L B$ constraint does not bind. The government optimally sets $\pi_{t}=1$.

Proposition 2: Long run tax (and debt) smoothing Assume that the ZLB constraint may bind up to some period $T>1$, after which no further shocks occur. Let $\tau_{t}^{s}$ denote the tax rate in the case where the $Z L B$ binds and $\tau_{t}^{n s}$ the tax in the no-shock case. We have $\tau_{t}^{n s}=\tau_{t}^{s}$ for $t=T+2, T+3, \ldots$ The value of government debt is identical in the two cases after $T+2$.

The two propositions above demonstrate that under complete markets all distortions stemming from inflation and taxes are fully eliminated in the long run (see $\mathrm{ABN}) .^{5}$

\footnotetext{
${ }^{4}$ See, for example, Chari and Kehoe (1999) for this derivation. Notice also that we have assumed that, initially, the government holds only short-maturity debt.

${ }^{5}$ If there are spending shocks remaining after period $T$, taxes will take longer to return to their steady-state level.
} 


\section{$3.2 \quad$ Optimal debt management}

We solve for the date 0 optimal portfolio that satisfies the intertemporal constraint in period 1 given tax policies. In order to gain some insights about the optimal debt-management strategy, we make the following two additional assumptions:

Assumption 2 Prices are fully rigid: $\theta=\infty$.

Assumption 3 The preference shock is serially uncorrelated: $\rho_{\xi}=0$.

Under Assumption 2, the government's intertemporal budget can be written as

$$
S_{1} \equiv \sum_{t=1}^{\infty} \beta^{t-1} \frac{u_{c}\left(c_{t}, \xi_{t}\right)}{u_{c}\left(c_{1}, \xi_{1}\right)} s_{t}=b_{0}^{1}+\beta^{N-1} \frac{u_{c}\left(c_{N}, \xi_{N}\right)}{u_{c}\left(c_{1}, \xi_{1}\right)} b_{0}^{N},
$$

where $b_{0}^{j} \equiv \frac{B_{t}^{j}}{P_{t}}$ represents the real payout of debt issued in period 0 and $S_{1}$ is the present value of the government's surpluses, which can take two possible values $\left\{S_{1}^{n s}, S_{1}^{s}\right\}$. The portfolio $\left(b_{0}^{1}, b_{0}^{N}\right)$ can complete the market if we can find a solution to the following system of equations:

$$
\left[\begin{array}{cc}
1 & \beta^{N-1} \frac{u_{c}\left(c_{N}^{n s}, 1\right)}{u_{c}\left(c_{1}^{n s}, 1\right)} \\
1 & \beta^{N-1} \frac{u_{c}\left(c_{N}^{s}, \xi_{N}\right)}{u_{c}\left(c_{1}^{s}, \xi_{1}\right)}
\end{array}\right] \cdot\left[\begin{array}{c}
b_{0}^{1} \\
b_{0}^{N}
\end{array}\right]=\left[\begin{array}{c}
S_{1}^{n s} \\
S_{1}^{s}
\end{array}\right] .
$$

Suppose now that $q_{1}^{N-1, n s} \equiv \beta^{N-1} \frac{u_{c}\left(c_{N}^{n s}, 1\right)}{u_{c}\left(c_{1}^{n s}, 1\right)} \neq q_{1}^{N-1, s} \equiv \beta^{N-1} \frac{u_{c}\left(c_{N}^{s}, \xi_{N}\right)}{u_{c}\left(c_{1}^{s}, \xi_{1}\right)}$. The unique solution to the above system of equations is

$$
\begin{aligned}
b_{0}^{1} & =-\frac{q_{1}^{N-1, n s} S_{1}^{s}-q_{1}^{N-1, s} S_{1}^{n s}}{q_{1}^{N-1, s}-q_{1}^{N-1, n s}} \\
b_{0}^{N} & =\frac{S_{1}^{s}-S_{1}^{n s}}{q_{1}^{N-1, s}-q_{1}^{N-1, n s}} .
\end{aligned}
$$

Whether the government issues long-term or short-term debt depends on how the present value of the government's surpluses and the price of bonds of maturity $N-1$ react to the shocks. If the shocks tend to move $S_{1}^{s}$ and $q_{1}^{N-1, s}$ in the same direction, then the optimal debt strategy is to issue long debt. As shown by $\mathrm{ABN}$, this would be the case if the economy were hit by public spending and/or technology shocks.

In order to characterize the optimal portfolio in our economy, we need to characterize the consumption response to the shocks. Combining (6) and (7) through solving for $\lambda_{f, t}$ (and noting that $\xi_{t}$ can be dropped) we have

$$
u_{c}\left(c_{t}\right)+v_{h}\left(h_{t}\right)-\lambda_{s} u_{c}\left(c_{t}\right) s_{h, t}-\lambda_{Z L B, t} u_{c c}\left(c_{t}\right)+\lambda_{Z L B, t-1} u_{c c}\left(c_{t}\right)-\lambda_{s} u_{c c}\left(c_{t}\right) s_{t}-\lambda_{s} u_{c}\left(c_{t}\right) s_{c, t}=0,
$$

where $s, s_{h}, s_{c}$ are all independent of $\xi_{t}$ and $h_{t}=c_{t}+g_{t}$ follows from the resource constraint.

Assume the preference shock hits in period 1 and let us - for now - abstract from public spending. From the condition above, one can see that if the ZLB binds, then $c_{t}=\bar{c}$ for $t=3,4,5, .$. (where $\bar{c}$ is the pre-shock level of consumption), $c_{1}<\bar{c}$ and $c_{2}>\bar{c}$. In other words, consumption will drop in period 1 and rise in period 2 . We can therefore state the following result:

Proposition 3. Under Assumptions 2 and 3, a negative preference shock that makes the ZLB bind raises the price of bonds of maturity $N-1$. Hence, $q_{1}^{N-1, s}>q_{1}^{N-1, n s}=\beta^{N-1}$. 
Using this result, system (11)-(12) implies that the government will issue short-term debt (i.e., $b_{0}^{1}>0$ and $\left.b_{0}^{N}<0\right)$ if the surplus falls in response to the preference shock, and long-term debt if the surplus rises. While Proposition 3 is established in the absence of spending shocks and under the restrictive assumptions 2 and 3, the numerical simulations that we undertake in the next section reveal that this result is extremely robust: the price of bonds always rises if the ZLB binds as a result of a negative preference shock. The rest of the analysis will therefore focus on the conditions under which the present value of government's surpluses falls, which would warrant issuing short-term debt. In section 5 , we will study optimal debt management when the value of public spending is set optimally.

\section{Numerical Simulations}

\subsection{Calibration}

In order to solve the model numerically, we need to specify a functional form for the utility function and to assign values to the structural parameters. We assume that household preferences are of the form $u\left(c_{t}, \xi_{t}\right)+v\left(h_{t}, \xi_{t}\right)=\xi_{t}\left[\log \left(c_{t}\right)+\zeta \log \left(1-h_{t}\right)\right]$. Each period represents a quarter, we therefore set $\beta=0.99$. We choose $\zeta$ so that households spend $20 \%$ of their unitary time endowment working, which gives $\zeta=3.0417$. To calibrate $\eta$ and $\theta$, we follow SGU (2004) and choose values of -6 and 17.5 , respectively. In steady state, the level of public expenditure is set to $25 \%$ of output.

To calibrate the preference shock process, we choose a value for $\xi_{1}$ that is low enough to make the ZLB bind. We maintain the assumption that $\rho_{\xi}=0$ as we found the qualitative features of the portfolio to be insensitive to the persistence of the shock. We study two versions of the model: one with zero initial debt and one in which the latter is strictly positive. Finally, we consider different values of $g_{1}$ and $\rho_{g}$.

\section{$4.2 \quad$ Results}

The results for the bond portfolios are reported in Table 1. We consider three different maturities for long-term bonds $(N=2,5,10)$ and report $\left(b_{0}^{1}, b_{0}^{N}\right)$ as fractions of steady-state GDP. The top and bottom panels of the table correspond to the cases with, respectively, zero and positive initial debt. In each case, we assume three scenarios about the increase in public spending in period 1. In the first scenario, spending remains constant; in the second, it increases by 5 percent relative to its steady-state level $(\bar{g})$, and in the the third scenario, it increases by 10 percent relative to $\bar{g}$.

Zero Initial Debt Starting with the case $\widetilde{B}_{-1}=0$, two main results emerge from Table 1. First, when government spending remains constant (at $\bar{g}$ ) it is optimal to set $b_{0}^{1}$ and $b_{0}^{N}$ approximately equal to zero. Second, when public spending increases, the optimal portfolio features long-term savings and short-term debt. To understand the optimal debt-management strategy, it is instructive to examine the response of consumption and taxes to the preference and spending shocks. These are plotted in Figure 1 under the assumptions $\rho_{g}=0$ (top panels) and $\rho_{g}=0.9$ (bottom panels). The solid lines show the case where $g_{t}=\bar{g}$, the dashed (crossed) line plots the response when the increase in spending is $5 \%(10 \%)$.

Consider first the solid line. As we previously established, a preference shock that makes the ZLB bind induces a drop in consumption in $t=1$, and a consumption boom in period $t=2$. To implement this allocation, the planner raises taxes in period 1 and lowers them in period 2. Because government spending is constant, the government's revenue therefore initially increases and subsequently drops, leaving the intertemporal budget nearly balanced. Hence, we have that $S_{1}^{s} \approx 0=S_{1}^{n s}$, which, given the discussion in the previous section, implies that the bond positions must also be close to 0 . Suppose that the government had set $b_{0}^{N}>>0>>b_{0}^{1}$. In this case, it is easy to show that the intertemporal constraint is violated with the tax adjustments shown in Figure 1, since the rise in the long-bond price increases the real payout of 
Table 1: Optimal Bond Portfolios.

\begin{tabular}{|c|c|c|c|c|c|c|}
\hline & \multicolumn{3}{|c|}{$\rho_{g}=0.0$} & \multicolumn{3}{|c|}{$\rho_{g}=0.9$} \\
\hline & $g_{1}=\bar{g}$ & $g_{1}=1.05 \times \bar{g}$ & $g_{1}=1.1 \times \bar{g}$ & $g_{1}=\bar{g}$ & $g_{1}=1.05 \times \bar{g}$ & $g_{1}=1.1 \times \bar{g}$ \\
\hline & \multicolumn{6}{|c|}{$\widetilde{B}_{-1}=0$} \\
\hline$\left(b_{0}^{1}, b_{0}^{2}\right)$ & $(-0.00,0.00)$ & $(0.29,-0.29)$ & $(0.58,-0.58)$ & $(-0.00,0.00)$ & $(2.60,-2.62)$ & $(5.15,-5.18)$ \\
\hline$\left(b_{0}^{1}, b_{0}^{5}\right)$ & $(-0.00,0.00)$ & $(0.34,-0.35)$ & $(1.25,-1.30)$ & $(-0.00,0.00)$ & $(2.58,-2.68)$ & $(6.75,-7.01)$ \\
\hline$\left(b_{0}^{1}, b_{0}^{10}\right)$ & $(-0.00,0.00)$ & $(0.34,-0.37)$ & $(1.25,-1.36)$ & $(-0.00,0.00)$ & $(3.27,-3.57)$ & $(15.43,-16.86)$ \\
\hline & \multicolumn{6}{|c|}{$\widetilde{B}_{-1}>0$} \\
\hline$\left(b_{0}^{1}, b_{0}^{2}\right)$ & $(-0.56,3.01)$ & $(0.70,1.73)$ & $(2.00,0.42)$ & $(-0.56,3.01)$ & $3.65,-1.23)$ & $(7.84,-5.45)$ \\
\hline$\left(b_{0}^{1}, b_{0}^{5}\right)$ & $(0.03,2.49)$ & $(0.35,2.27)$ & $(1.37,1.10)$ & $(0.02,2.50)$ & $(3.67,-1.28)$ & $(9.86,-7.72)$ \\
\hline$\left(b_{0}^{1}, b_{0}^{10}\right)$ & $(0.02,2.68)$ & $(0.35,2.27)$ & $(1.37,1.15)$ & $(0.02,2.62)$ & $(4.04,-1.75)$ & $(22.60,-22.06)$ \\
\hline
\end{tabular}

Notes: The table shows the optimal bond portfolios in the case of zero initial debt (top panels) and positive initial debt (bottom panels). In the latter case we have assumed that the debt to GDP ratio (at yearly horizon) is 60 percent (at quarterly horizon is 240 percent). $N=2,5,10$ denotes the maturity of the long bond. The 1st and 4th columns consider the case where there is no shock to spending; in columns 2 and 5 the shock is a 5 percent increase relative to $\bar{g}$ and finally columns 3 and 6 consider the case of a 10 percent increase in spending. In the first three columns the spending shock is i.i.d and in columns 4-6 we assume a first-order autocorrelation coefficient of 0.9.

government debt. Tax rates would need to increase permanently to satisfy (10). The converse holds when $b_{0}^{1}>>0$. To ensure long-run tax smoothing, the bond positions must remain virtually nil.

The rise in $g_{1}$ has two distinct effects: First, because consumption is separable from leisure, higher spending levels decrease $c_{1}$ further. This means that $c_{2}$ need not increase to satisfy the ZLB constraint. In fact, $c_{2}$ declines in response to the shock and this decline is larger the larger and the more persistent the increase in public spending, as can be seen from Figure 1. This effect tends to attenuate the increase in $q_{1}^{N-1, s}$. Second, an increase in public spending lowers the present value of surpluses $\left(S_{1}^{s}<S_{1}^{n s}\right)$. This in turn implies that the government must issue short-maturity debt to complete the market. Note, however, that while short-term debt remains optimal when $g_{1}$ or $\rho_{g}$ increases, the value of the bond positions relative to GDP increases. The government now needs to fan out the bond positions to exploit the smaller variations in the yield curve.

Positive Initial Debt Consider now the more empirically plausible scenario of positive initial debt $\left(\widetilde{B}_{-1}>0\right)$. In the bottom panel of Table 1 , we have set $\widetilde{B}_{-1}$ equal to $60 \%$ of steady-state GDP (over an annual horizon, $240 \%$ at a quarterly horizon). There are several noteworthy features. When spending shocks are not substantial, the optimal debt management strategy is now to issue long debt. As the spending shock becomes larger, the value of short debt increases. When the spending shock is both large and persistent, we again obtain a portfolio with short debt only.

To understand these patterns, recall that with zero initial debt, the condition for short bonds to be optimal $\left(S_{1}^{s}<S_{1}^{n s}\right)$ is likely to be satisfied because the surpluses $s_{t}$ are zero for $t=3,4, \ldots$ When $\widetilde{B}_{-1}>0$, however, strictly positive values of $s_{t}$ are needed to finance the debt level. When the preference shock hits, the present value of surpluses, $S_{1}^{s}$, increases because the terms $s_{t}$ are now discounted less heavily in the intertemporal budget. Unless the government increases $g$ considerably (and persistently), issuing short debt only cannot be optimal. 
Figure 1: Response of Consumption and Taxes.
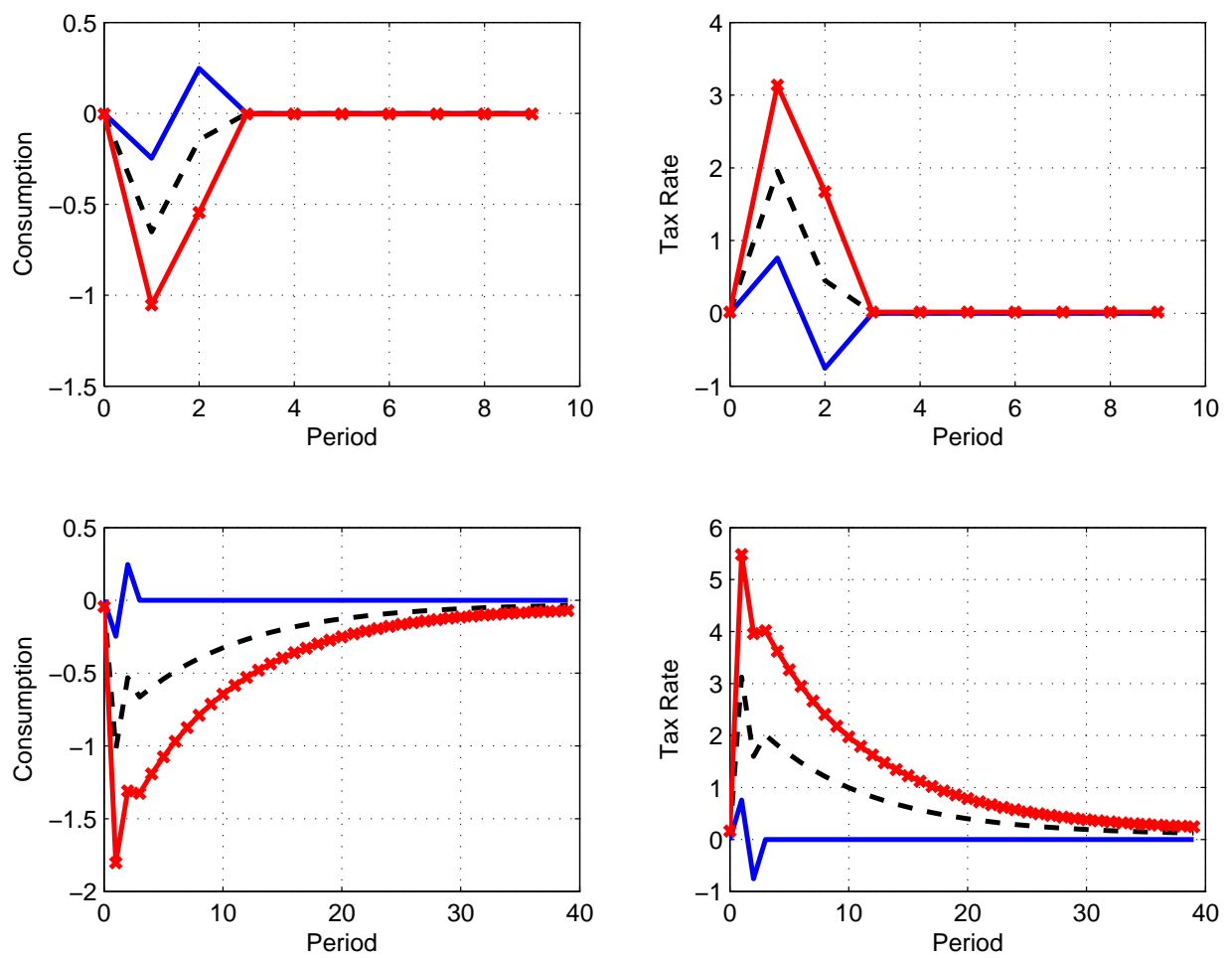

Notes: The figure plots the response of consumption (left) and taxes (right) to the preference shocks. The solid lines show the responses when spending remains constant. The dashed lines show the case where the shock in spending is a 5 percent increase relative to steady state and the crossed line the case where the shock increases spending by 10 percent. In the top panels we assume $\rho_{g}=0$. In the bottom panels $\rho_{g}=0.9$. All graphs show the percentage change of a variable relative to its steady-state value.

\section{$5 \quad$ What if Government Spending is Chosen Optimally?}

The previous section suggests that, following a preference shock that makes the ZLB constraint bind, governments want to issue short debt if the spending shocks are substantial and initial debt levels moderate. We now ask: how would our conclusions be affected if we let the planner choose the level of $g$ in every period. For this purpose, we assume that households' preferences can be represented by $u\left(c_{t}, \xi_{t}\right)+v\left(h_{t}, \xi_{t}\right)+\omega\left(g_{t}, \xi_{t}\right)=\xi_{t}\left[\log \left(c_{t}\right)+\zeta \log \left(1-h_{t}\right)+\psi \log \left(g_{t}\right)\right]$, where the value of $\psi$ is such that government expenditures in the deterministic steady state equal 25 percent of GDP.

Under these assumptions, the first-order condition with respect to $g$ is

$$
\omega_{g}\left(g_{t}, \xi_{t}\right)-\lambda_{f, t}+\lambda_{s} u_{c}\left(c_{t}, \xi_{t}\right)=0
$$

The optimality conditions for the other endogenous variables are the ones we derived previously. Combining (13) with (6) and assuming again $\theta=\infty$, we obtain ${ }^{6}$

$$
u_{c}\left(c_{t}\right)-\omega_{g}\left(g_{t}\right)-\lambda_{s} u_{c}\left(c_{t}\right)-\lambda_{Z L B, t} u_{c c}\left(c_{t}\right)+\lambda_{Z L B, t-1} u_{c c}\left(c_{t}\right)-\lambda_{s} u_{c c}\left(c_{t}\right) s_{t}-\lambda_{s} u_{c}\left(c_{t}\right) s_{c, t}=0 .
$$

From this equation we can show that $g_{t} \neq \bar{g}$ only if $\lambda_{Z L B, t}$ or $\lambda_{Z L B, t-1}$ are different from zero. This

\footnotetext{
${ }^{6} \xi_{t}$ can again be dropped from the resulting expression.
} 
provides a microfoundation for Assumption 1, namely, that government spending increases when the shock to preferences is large enough to make the ZLB bind. The difference here is that when $g$ is a choice variable, its response need not conform with the simple $\mathrm{AR}(1)$ process we previously assumed.

In Figure 2, we show the behavior of government spending, consumption and taxes in response to a preference shock of the same size considered in the simulations above, under the assumption of zero initial debt. As can be seen from the figure, $g$ increases in period 1 but decreases in period 2 . In percentage terms, the increase in $g$ in $t=1$ is minuscule and is almost fully offset by the drop in $t=2$. The economy returns to steady state at $t=3$, so that the surpluses, $s_{t}$, become nil from that date onwards. In the bottom panel of Figure 2, we have multiplied the preference shock by a factor of 10. Even in this case, we continue to obtain a moderate initial increase in spending, half of which is lost in $t=2$.

Figure 2: Response of Spending, Consumption and Taxes: Case with Optimal Public Spending.
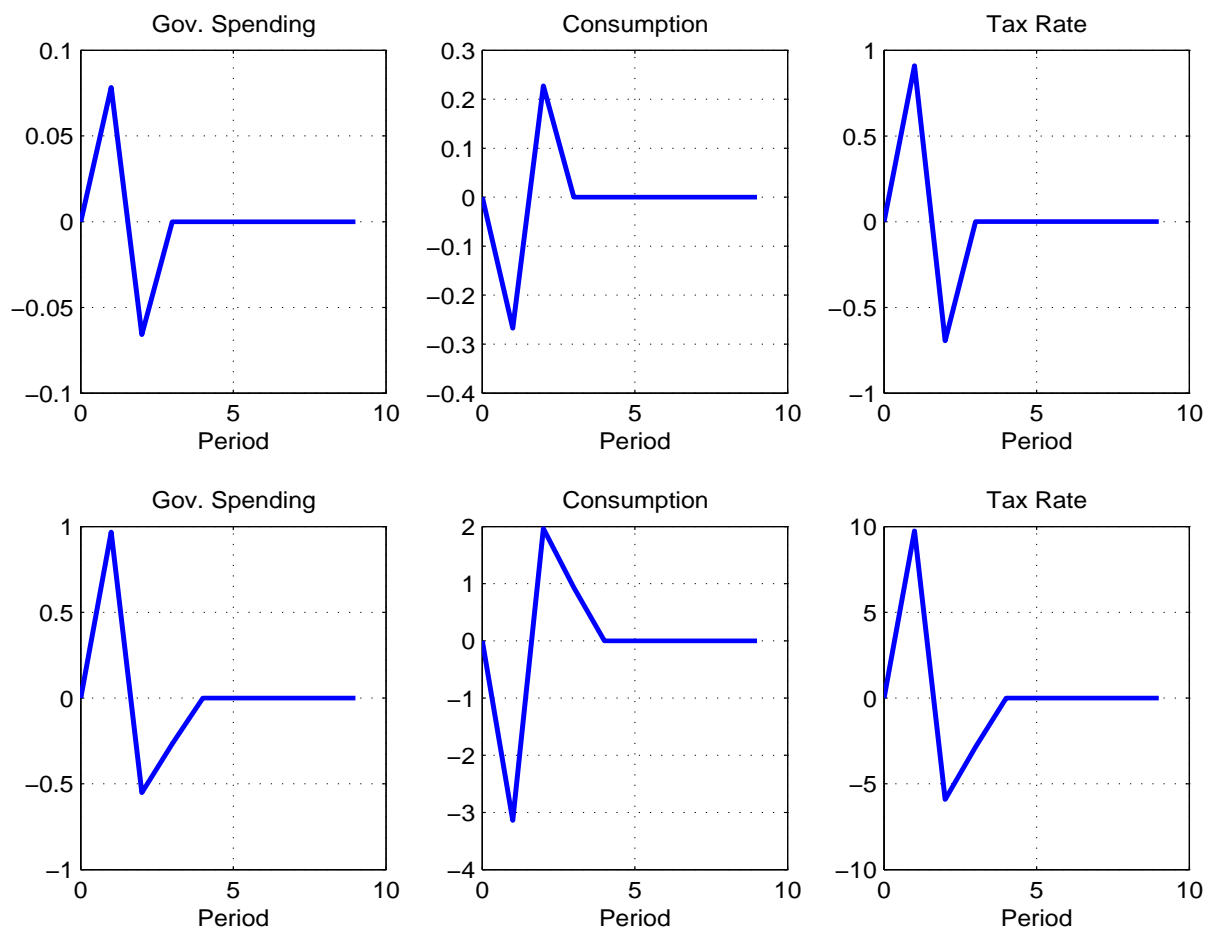

Notes: The figure plots the response of public spending, consumption and taxes to the preference shocks in the case with optimal public spending. The top panel utilizes the benchmark shock (the same as in Figure 1). The bottom panel multiplies the shock by a factor of 10. All graphs show the percentage change of a variable relative to its steady-state value.

Turning to the optimal portfolios, Table 2 shows that it is optimal to issue long-term debt across all values of $\widetilde{B}_{-1}$ regardless of the size of the preference shock. As we have shown in section 4.2 , the government finds it optimal to issue short bonds when shocks to public spending are substantial, especially when initial debt is large. In the case where $g$ becomes a choice variable, this condition is clearly not satisfied; it is optimal to finance the initial liability using long-term debt only.

\section{Conclusion}

We have demonstrated that governments facing the risk of falling into a liquidity trap may find it optimal to issue short-term debt if their initial liability is moderate and if the amount of public spending they 
Table 2: Optimal Bond Portfolios: Case with Optimal Public Spending.

\begin{tabular}{cccccc}
\hline \hline & \multicolumn{2}{c}{ Benchmark Shock } & & \multicolumn{2}{c}{ Large Shock } \\
\cline { 2 - 3 } \cline { 5 - 6 } & $\widetilde{B}_{-1}=0$ & $\widetilde{B}_{-1}>0$ & & $\widetilde{B}_{-1}=0$ & $\widetilde{B}_{-1}>0$ \\
\hline$\left(b_{0}^{1}, b_{0}^{2}\right)$ & $(-0.03,0.03)$ & $(-0.55,3.01)$ & & $(-0.06,0.06)$ & $(-4.69,7.18)$ \\
$\left(b_{0}^{1}, b_{0}^{5}\right)$ & $(-0.03,0.03)$ & $(-0.01,2.53)$ & & $(-0.02,0.02)$ & $(-0.01,2.53)$ \\
$\left(b_{0}^{1}, b_{0}^{10}\right)$ & $(-0.03,0.03)$ & $(-0.01,2.66)$ & & $(-0.02,0.02)$ & $(-0.01,2.66)$ \\
\hline \hline
\end{tabular}

Notes: The table shows the optimal bond portfolios in the case with optimal public spending. The first columns assumes that initial debt is equal to zero. The second column assumes an initial debt level of 240 percent of GDP at quarterly horizon.

need to finance is sufficiently large and persistent. This will not be the case, however, if public spending is chosen optimally. Our analysis is a first step towards a broader agenda that seeks to integrate the standard macro model of debt management with the "finance view", which attributes changes in bond prices to movements in the relative supply of long and short debt. This strand of the literature suggests that buying back long bonds from the secondary market may lower interest rates by exerting price pressure effects (see for example Greenwood and Vayanos (2010)); a channel from which our model abstracts, but which is an important aspect of debt management in a liquidity trap.

\section{References}

[1] Aiyagari, R., Marcet, A., Sargent, T.J. and Seppälä, J. (2002) "Optimal Taxation without StateContingent Debt", Journal of Political Economy, 110, 1220-1254.

[2] Angeletos, G-M. (2002) "Fiscal Policy with Non-contingent Debt and Optimal Maturity Structure", Quarterly Journal of Economics, 27, 1105-1131.

[3] Buera F. and Nicolini, J.P. (2006) "Optimal Maturity of Government Debt with Incomplete Markets", Journal of Monetary Economics, 51, 531-554.

[4] Christiano L., Eichenbaum M. and S. Rebelo (2011) "When Is the Government Spending Multiplier Large?" Journal of Political Economy, 119, 78-121.

[5] Eggertsson G.B. and Woodford M. (2003) "The Zero Bound on Interest Rates and Optimal Monetary Policy?" Brookings Papers on Economic Activity,119.

[6] Faraglia, E, Marcet, A., Oikonomou, R. and Scott, A. (2013) "The Impact of Debt Levels and Debt Maturity on Inflation", Economic Journal, 123, 164-192.

[7] Faraglia, E., Marcet, A., Oikonomou, R. and Scott, A. (2015) "Government Debt Management: The Long and Short of It ", London Business School mimeo.

[8] Greenwood, R. and Vayanos, D (2008) "Bond Supply and Excess Bond Returns", CEPR Discussion Papers 6694, C.E.P.R. Discussion Papers.

[9] Lustig, H., Sleet, C., Yeltekin, S., (2009) "Fiscal Hedging with Nominal Assets", Journal of Monetary Economics 55, 710-727. 
[10] Marcet, A. and Scott, A. (2009) "Debt and Deficit Fluctuations and the Structure of Bond Markets", Journal of Economic Theory 144 (2009) 473-501.

[11] Nosbusch, Y. (2008) "Interest Costs and the Optimal Maturity Structure of Government Debt", Economic Journal, 118, 477-498.

[12] Rotemberg, J. (1982) "Sticky Prices in the United States", Journal of Political Economy, 90, 11871211.

[13] Schmitt-Grohé, S and Uribe, M. (2004), "Optimal Fiscal and Monetary Policy Under Sticky Prices", Journal of Economic Theory, 114, 198-230.

\section{A Appendix}

Proof of Proposition 1 Consider equation (8) and set $\lambda_{Z L B, t}=\lambda_{Z L B, t-1}=0$ (from complementary slackness). Then, we have that

$$
-\theta \lambda_{f, t}\left(\pi_{t}-1\right)-\left(\lambda_{p, t}-\lambda_{p, t-1}\right) u_{c}\left(c_{t}, \xi_{t}\right)\left(2 \pi_{t}-1\right)=0
$$

Moreover, since $s_{w, t}=h_{t}$, from equation (9), we have $\lambda_{s}-\frac{\eta}{\theta} \lambda_{p, t}=0$, meaning that $\lambda_{p, t}=\lambda_{p}$ is constant. Equation (8) gives $-\theta \lambda_{f, t}\left(\pi_{t}-1\right)=0$. Hence, $\pi_{t}=1$.

Proof of Proposition 2 Since inflation equals zero when $\lambda_{Z L B, t}=\lambda_{Z L B, t-1}$, then $w_{t}=\frac{1+\eta}{\eta}$ and we have from equations (6) and (7)

$$
u_{c}\left(c_{t}, \xi_{t}\right)+v_{h}\left(h_{t}, \xi_{t}\right)-\lambda_{s} u_{c}\left(c_{t}, \xi_{t}\right) s_{h, t}-\lambda_{s} u_{c c}\left(c_{t}, \xi_{t}\right) s_{t}-\lambda_{s} u_{c}\left(c_{t}, \xi_{t}\right) s_{c, t}=0
$$

Noting that $\xi_{t}$ can be dropped from the above equation (since it multiplies each one of the terms) and replacing $g_{t}=\bar{g}$ (hence $c_{t}+\bar{g}=h_{t}$ ), we have that

$$
u_{c}\left(c_{t}\right)+v\left(c_{t}+\bar{g}\right)-\lambda_{s} u_{c}\left(c_{t}\right) s_{h, t}-\lambda_{s} u_{c c}\left(c_{t}, \xi_{t}\right) s_{t}-\lambda_{s} u_{c}\left(c_{t}, \xi_{t}\right) s_{c, t}=0
$$

where $s_{c, t} \equiv \frac{v_{h}\left(c_{t}+\bar{g}\right)}{u_{c}\left(c_{t}\right)^{2}} u_{c c}\left(c_{t}\right)\left(c_{t}+\bar{g}\right)$ and $s_{h, t}=\frac{v_{h h}\left(c_{t}+\bar{g}\right)}{u_{c}\left(c_{t}\right)}\left(c_{t}+\bar{g}\right)+\left(1+\frac{v_{h}\left(c_{t}+\bar{g}\right)}{u_{c}\left(c_{t}\right)} \frac{\eta}{1+\eta}\right) \frac{1+\eta}{\eta}$.

Notice that the equation above holds also in the case of no shocks. Therefore, the solution to this equation is the same consumption level that we obtain if the preference and the government spending shocks were muted. Since hours equal $\bar{g}+$ this consumption level, we also have that hours are constant. Thus, the surplus is the same as in the no-shock economy.

We now turn to the debt levels in period $t$. Notice that for government debt to be solvent it needs to satisfy the intertemporal budget. Moreover, since uncertainty is removed from the model after period 1, it is easy to show that only one maturity is sufficient to complete the market. Let us therefore assume that the government from period 1 onwards issues short maturity debt for all $t$. We then have

$$
\sum_{j=1}^{\infty} \beta^{j-1} \frac{u_{c}\left(c_{t+j}, 1\right)}{u_{c}\left(c_{t}, 1\right)}\left[\bar{g}+\left(1+\frac{v_{h}\left(h_{t+j}\right)}{u_{c}\left(c_{t+j}, 1\right) w_{t+j}}\right) w_{t+j} h_{t+j}\right]=b_{t}^{1}
$$

which gives the same debt level in the case where the shock hits and the no-shock case.

Proof of Proposition 3 The price equals 1 when $N=2$ and the ZLB is binding. When $N>2$ we can establish that $\beta^{N-1} \frac{u_{c}\left(c_{N}^{s}, 1\right)}{u_{c}\left(c_{1}^{s}, \xi_{1}\right)}=\beta \frac{u_{c}\left(c_{2}^{s}, 1\right)}{u_{c}\left(c_{1}^{s}, \xi_{1}\right)} \beta^{N-2} \frac{u_{c}\left(c_{N}^{s}, 1\right)}{u_{c}\left(c_{2}^{s}, 1\right)}$. Since $c_{2}>\bar{c}$ and $c_{N}=\bar{c}$, the term $\frac{u_{c}\left(c_{N}^{s}, 1\right)}{u_{c}\left(c_{2}^{s}, 1\right)}$ exceeds 1. 
Institut de Recherches Économiques et Sociales

Université catholique de Louvain

Place Montesquieu, 3

1348 Louvain-la-Neuve, Belgique 